\section{Case Reports in Dermatology}

Case Rep Dermatol 2021;13:148-153

DOI: $10.1159 / 000512710$

Published online: February 26, 2021 (c) 2021 The Author(s)

Published by S. Karger AG, Basel www.karger.com/cde

\title{
Varicella Zoster Virus-Associated Meningitis as a Rebound Varicella Zoster Disease after Antiviral Discontinuation
}

\author{
Tetsuko Sato ${ }^{a}$ Takenobu Yamamoto ${ }^{a, b} \quad$ Yumi Aoyama $^{a}$ \\ aDepartment of Dermatology, Kawasaki Medical School, Kurashiki, Japan; ${ }^{b}$ Department of \\ Dermatology, Kawasaki Medical School General Medical Center, Kurashiki, Japan
}

\section{Keywords}

Varicella zoster virus · Herpes zoster · Meningitis · Rebound phenomenon · Acyclovir

\begin{abstract}
Varicella zoster virus (VZV)-associated meningitis is usually progressive and can be fatal, and early diagnosis and aggressive treatment with intravenous antivirals such as acyclovir (ACV) are required in immunocompromised patients. Patients receiving corticosteroids and immunosuppressive therapy have a significantly higher risk of VZV-associated meningitis. In this report, we describe an unusual case of herpes zoster $(\mathrm{HZ})$ in a young woman who was first diagnosed during tapering of prednisone for dermatomyositis. The skin lesions affected the left $L 2$ and $L 3$ dermatomes, which is unusual in VZV-associated meningitis. Despite showing a good rapid response to antivirals, she developed VZV-associated meningitis immediately after discontinuation of ACV. This phenomenon is often called rebound VZV reactivation disease and occurs after discontinuation of antivirals. This case was notable in that the affected dermatomes were distant from the cranial nerves. Thus, progression of HZ to VZV reactivationassociated meningitis can occur even in appropriately treated $\mathrm{HZ}$ patients. Continuation of antivirals beyond 1 week in patients on immunosuppressive therapy may be associated with a decreased risk of severe rebound VZV disease, such as VZV-associated meningitis.
\end{abstract}




\section{Case Reports in Dermatology}

Case Rep Dermatol 2021;13:148-153

DOI: $10.1159 / 000512710$

(c) 2021 The Author(s). Published by S. Karger AG, Basel www.karger.com/cde

Sato et al.: Varicella Zoster Virus Meningitis as Viral Rebound

\section{Introduction}

Reactivation of latent varicella zoster virus (VZV) typically results in the clinical syndrome of herpes zoster (HZ), but the virus is also responsible for atypical clinical presentations, particularly in immunocompromised patients. HZ has been widely described in the setting of various systemic autoimmune diseases, and a recent nationwide population-based cohort study in Taiwan demonstrated that dermatomyositis (DM)/polymyositis (PM) was associated with an increased risk of subsequent $\mathrm{HZ}$ compared with the absence of DM/PM in both women and men [1]. In addition, patients with DM/PM on immunosuppressive therapy had a significantly higher risk of $\mathrm{HZ}$ [1]. Although the most common complication of $\mathrm{HZ}$ is postherpetic neuralgia, other serious complications that may occur include VZV-associated meningitis, meningoencephalitis, encephalitis, myelopathy, and vasculopathy [2]. These diseases are usually progressive and can be fatal; therefore, early diagnosis and aggressive treatment with intravenous antivirals are required in immunocompromised patients.

In this report, we describe an unusual case of $\mathrm{HZ}$ in a young woman; the diagnosis was first made during tapering of corticosteroids for DM, and the skin lesions affected the left L2 and L3 dermatomes, which is unusual in VZV-associated meningitis. Although she showed a good rapid response in the vesicles to treatment with intravenous acyclovir (ACV), she returned to our hospital 3 days after discharge with acute onset of severe headache and widespread erythematous lesions on her left thigh. The development of these serious complications immediately after withdrawal of ACV while receiving mycophenolate mofetil (MMF) therapy raised suspicion that VZV reactivation triggered by tapering of corticosteroids was exacerbated by the withdrawal of ACV and that rebound VZV reactivation contributed to this classic but serious complication seen in patients on immunosuppressive therapy. There is no consensus on how long antivirals should be given to patients on immunosuppressive therapy because of concerns over rebound VZV disease after the discontinuation of antivirals.

\section{Case Report}

A 38-year-old woman with DM presented with a 3-day history of multiple painful grouped vesiculobullous lesions distributed along the left L2 and L3 dermatomes (day 1). She had no past history of diabetes, HIV, or other immunodeficiency. She had received prednisone 20 $\mathrm{mg}$ /day) plus MMF (1.5 g/day) for 2 months. The onset of $\mathrm{HZ}$ coincided with tapering of the corticosteroids to $10 \mathrm{mg} /$ day. After starting oral famciclovir $30 \mathrm{mg} / \mathrm{kg}$ for 1 day following intravenous ACV $750 \mathrm{mg} /$ day for 5 days, the lesions started healing with crusting and postinflammatory pigmentation. She was discharged with a prescription for prednisone and MMF.

Two days after discontinuation of ACV, she developed severe intermittent headaches with fever, cervical rigidity, and multiple erythematous papules and plaques on the left thigh (day 17; Fig. 1). There was no mucosal involvement or lymphadenopathy. Because the severe headaches did not improve with NSAID use, lumbar puncture was performed to investigate the cause of the headache. Adverse effects of MMF were suspected, and it was discontinued, but the clinical symptoms rapidly deteriorated. The patient reported having fever, but no paresthesia, vision changes, or hearing loss.

Laboratory tests revealed normal white blood cell counts $(7,830 / \mu \mathrm{L}, 76 \%$ lymphocytes) and C-reactive protein levels $(0.36 \mathrm{mg} / \mathrm{dL})$. Cerebrospinal fluid (CSF) analysis showed an

\section{Karger'=}




\section{Case Reports in Dermatology}

Case Rep Dermatol 2021;13:148-153

DOI: $10.1159 / 000512710$

(c) 2021 The Author(s). Published by S. Karger AG, Basel www.karger.com/cde

Sato et al.: Varicella Zoster Virus Meningitis as Viral Rebound

elevated white blood cell count of $45.3 / \mu \mathrm{L}$ (96.3\% mononuclear cells) and elevated protein levels of $109 \mathrm{mg} / \mathrm{dL}$ (reference range: 10-40 mg/dL). VZV DNA was detected by PCR in the CSF viral panel. The VZV DNA load on day 17 was $1.9 \times 10^{2}$ copies $/ \mathrm{mL}$ in saliva, undetectable in blood, and $6.0 \times 10^{4} \mathrm{copies} / \mathrm{mL}$ in CSF. We diagnosed aseptic meningitis due to VZV reactivation and VZV-induced erythema multiforme (EM).

Histological examination of a skin biopsy showed perivascular lymphocytic infiltrates in the papillary dermis with few histiocytes. VZV immunostaining of the skin tissue was interpreted as positive, with glycoprotein E detected only at crusts formed in the upper epidermis. She was started on intravenous ACV 1,500 mg/day with concurrent prednisone $10 \mathrm{mg} /$ day, and the headaches completely resolved thereafter (Fig. 2). At a follow-up examination 6 months after the episode of meningitis, the patient was completely free of any central nervous system symptoms.

\section{Discussion}

Aseptic meningitis is a relatively rare neurologic complication of $\mathrm{HZ}$, occurring in approximately $0.5 \%$ of patients diagnosed with recent $\mathrm{HZ}$ [3]. According to a retrospective study that investigated potential risk factors for aseptic meningitis in patients with HZ [4], VZV-associated aseptic meningitis occurred more frequently in patients with skin lesions affecting the craniocervical distribution (87.5\%) compared with the thoracic $(12.5 \%)$, lumbar $(0 \%)$, and sacral $(0 \%)$ dermatomes. These observations suggest the possibility that a close anatomical distance to the involved nerves could facilitate viral invasion of the brain meninges. In this regard, our patient was notable in that the involved dermatomes were distant from the cranial nerves. She did not have contiguity between the meningitis and dermatomal levels, suggesting that the virus may have arisen at different spiral root ganglia. This appears consistent with previous work suggesting that the virus could spread via blood vessels in the central nervous system [5].

Variable time periods have been reported between the onset of $\mathrm{HZ}$ and the symptoms of meningitis, ranging from 1 to 9 days after the initiation of antiviral therapy [6]. Kim et al. [4] reported that the mean interval was 5.3 days and suggested that symptoms of meningitis appeared within 6 days from onset of HZ lesions. Given that patients with HZ are usually treated with ACV at a dose of $5-10 \mathrm{mg} / \mathrm{kg}$ body weight 3 times daily for at least 7 days, many patients are likely to develop aseptic meningitis during antiviral therapy. Interestingly, our patient developed aseptic meningitis and EM lesions 2 days after discontinuation of antiviral therapy, unlike in other reported cases. This phenomenon is often called rebound VZV reactivation disease, which occurs after discontinuation of antivirals [7]. Thus, physicians must be aware that VZV-associated meningitis and EM can occur after the end of treatment with an anti-VZV agent as a late complication. The progression of $\mathrm{HZ}$ to $\mathrm{VZV}$-associated meningitis occurred even in appropriately treated $\mathrm{HZ}$ patients.

The critical question is what additional factors could be responsible for the development of aseptic meningitis and EM after the end of successful treatment. One possibility is that rebound replication of VZV may have occurred upon discontinuation of antiviral treatment during immunosuppressive therapy. Although discontinuation or reduction of immunosuppressive therapy upon diagnosis of VZV-associated aseptic meningitis seems to be intuitively rational, abrupt reduction of immunosuppressive therapy could paradoxically result in rebound of pathogenic inflammatory responses to VZV, thereby leading to severe meningitis. Thus,

\section{Karger'}




\section{Case Reports in Dermatology}

Case Rep Dermatol 2021;13:148-153

DOI: $10.1159 / 000512710$

C 2021 The Author(s). Published by S. Karger AG, Basel www.karger.com/cde

Sato et al.: Varicella Zoster Virus Meningitis as Viral Rebound

maintaining the dose of immunosuppressive agents despite the occurrence of VZV-associated meningitis might be appropriate in the management of these patients to avoid severe meningitis. Although there are no established guidelines for the treatment of $\mathrm{HZ}$ in patients on immunosuppressive therapy, these patients may require a higher dose of antivirals (e.g., 10 $\mathrm{mg} / \mathrm{kg}$ every $8 \mathrm{~h}$ ) for a prolonged period (up to 2 weeks) [8].

In conclusion, the progression of $\mathrm{HZ}$ to aseptic meningitis may occur more frequently in patients on immunosuppressive therapy than previously thought, even when they are treated with appropriate antiviral therapy. HZ patients with DM on immunosuppressive therapy may be at particularly high risk of progressing to aseptic meningitis. To identify patients at high risk of progressing to meningitis, patients with $\mathrm{HZ}$ who develop severe headache should undergo CSF analysis via PCR. Continuation of high-dose antivirals beyond 1 week in patients on immunosuppressive therapy may be associated with a decreased risk of severe rebound VZV reactivation diseases, such as VZV-associated meningitis.

\section{Statement of Ethics}

The study was approved by the Institutional Review Board at Kawasaki Medical University and followed the guidelines for the ethical conduct of human research. Written informed consent was obtained from the patient for publication of this case report and any accompanying images.

\section{Conflict of Interest Statement}

The authors report no conflicts of interest.

\section{Funding Sources}

This study was supported by Kawasaki Medical School. This work was partially supported by grants from the Japan Agency for Medical Research and Development (20ek0410068h0001).

\section{Author Contributions}

All authors contributed to the design of the study, data collection, and manuscript preparation. All authors have read the manuscript and have approved its submission.

\section{References}

1 Tsai SY, Lin CL, Wong YC, Yang TY, Kuo CF, Cheng JM, et al. Increased Risk of Herpes Zoster Following Dermatomyositis and Polymyositis: A Nationwide Population-Based Cohort Study. Medicine (Baltimore). 2015 Jul;94(28):e1138.

2 Gilden D, Nagel M, Cohrs R, Mahalingam R, Baird N. Varicella Zoster Virus in the Nervous System. F1000 Res. 2015 Nov;4(1356):1356.

\section{Karger'=}




\section{Case Reports in Dermatology}

\begin{tabular}{l|l}
\hline Case Rep Dermatol 2021;13:148-153 \\
\hline DOI: 10.1159/000512710 & $\begin{array}{l}\text { (c) 2021 The Author(s). Published by S. Karger AG, Basel } \\
\text { www.karger.com/cde }\end{array}$ \\
\hline
\end{tabular}

Sato et al.: Varicella Zoster Virus Meningitis as Viral Rebound

3 Gupta P, Ranjan R, Agrawal CS, Muralikrishnan K, Dave N, Rana DS. Meningitis with polymerase chain reaction for varicella zoster positivity in cerebrospinal flid of a young immunocompetent adult. J Neurosci Rural Pract. 2016 Oct-Dec;7(4):591-3.

4 Kim SH, Choi SM, Kim BC, Choi KH, Nam TS, Kim JT, et al. Risk Factors for Aseptic Meningitis in Herpes Zoster Patients. Ann Dermatol. 2017 Jun;29(3):283-7.

5 Grahn A, Studahl M. Varicella-zoster virus infections of the central nervous system - prognosis, diagnostics and treatment. J Infect. 2015 Sep;71(3):281-93.

6 Braun-Falco M, Hoffmann M. Herpes zoster with progression to acute varicella zoster virusmeningoencephalitis. Int J Dermatol. 2009 Aug;48(8):834-9.

7 Boeckh M, Kim HW, Flowers ME, Meyers JD, Bowden RA. Long-term acyclovir for prevention of varicella zoster virus disease after allogeneic hematopoietic cell transplantation - a randomized double-blind placebo-controlled study. Blood. 2006 Mar;107(5):1800-5.

8 Dworkin RH, Johnson RW, Breuer J, Gnann JW, Levin MJ, Backonja M, et al. Recommendations for the management of herpes zoster. Clin Infect Dis. 2007;44 Suppl 1:S1-S26.

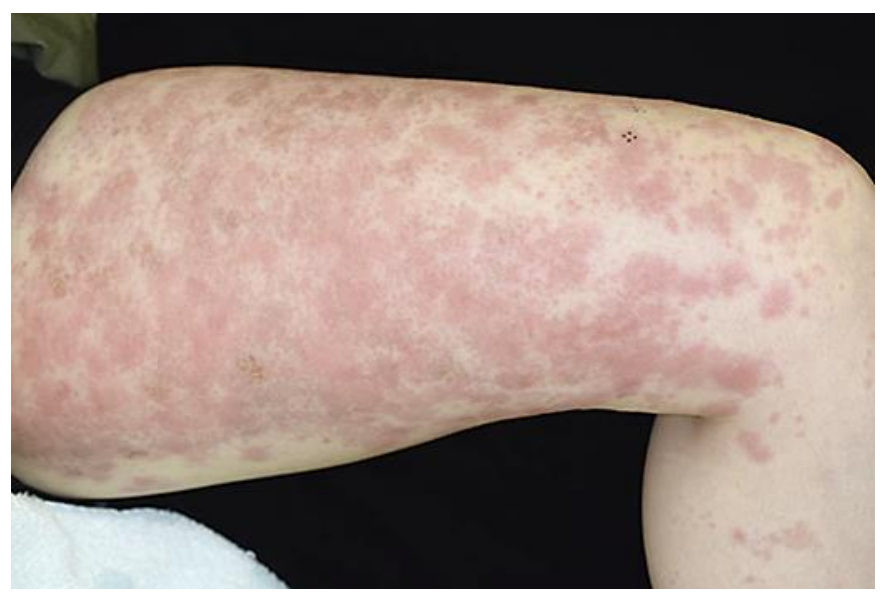

Fig. 1. Clinical image showing widespread erythema and follicular papules after the cessation of acyclovir. 
Case Reports in Dermatology www.karger.com/cde

Sato et al.: Varicella Zoster Virus Meningitis as Viral Rebound
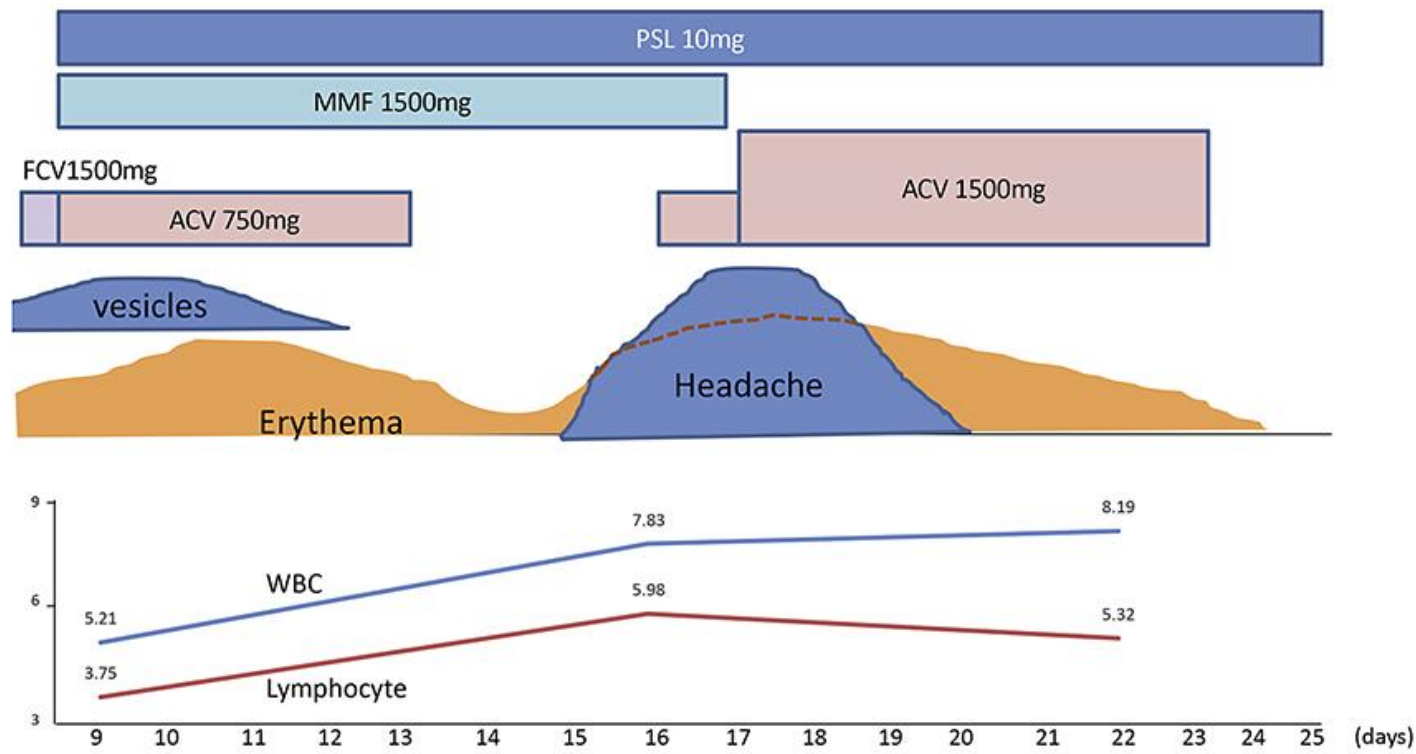

\section{Serum VZV-IgG}

11.6

CSF VZV DNA $6.0 \times 10^{4}$ copies $/ \mathrm{ml}$

Fig. 2. Clinical symptoms and laboratory findings in this case with reactivation of VZV in relation to treatment. ACV, acyclovir; CSF, cerebrospinal fluid; FCV, famciclovir; MMF, mycophenolate mofetil; PSL, prednisone; VZV, varicella zoster virus; WBC, white blood cell count. 